\title{
MANAJEMEN KURIKULUM BERBASIS KERANGKA KUALIFIKASI NASIONAL INDONESIA (KKNI) DI PERGURUAN TINGGI ISLAM
}

\author{
Adlan Fauzi Lubis \\ Program Studi Pendidikan Agama Islam, Universitas Muhammadiyah Jakarta, \\ Banten, Indonesia \\ Email: adlanfauzi@umj.ac.id
}

DOI:http://doi.org/10.33650/al-tanzim.v4i2.1248

\begin{tabular}{l|l|l} 
Received: June 2020 & Accepted: August 2020 & Published: September 2020
\end{tabular}

\begin{abstract}
:
The purpose of this study was to analyze planning, implementation, and evaluation of curriculum development based on Indonesian National Qualification Framework (KKNI) in the Islamic Education Department at Muhammadiyah University, Jakarta. This research uses qualitative approach. Interviews were conducted directly with informants consisting of the Dean, Vice Dean, Head of Islamic Education Department. The results of observations and documentation were obtained from various studies of documents, manuscripts, and archives related to the KKNI-based curriculum management. Data analysis is based on data reduction, data display, and verification. The result of this study figures out that: a) The curriculum of the Islamic Education Department at UMY has been approved in accordance with the KKNI curriculum and each components of curriculum management consist of planning, implementing, and evaluating of the curriculum although there are deficiencies in each process; $b$ ) The development of curriculum management needs attention to Standard Operational Procedures and curriculum arrangements for the KKNI although its implementation is not entirely based on the KKNI.
\end{abstract}

Keywords: curriculum management, Islamic higher education, KKNI

Abstrak:

Penelitian ini bertujuan untuk menganalisis tentang penyusunan, pelaksanaan dan evaluasi dalam pengembangan kurikulum berbasis Kerangka Kualifikasi Nasional Indonesia (KKNI) pada prodi Pendidikan Agama Islam (PAI) di Universitas Muhammadiyah Jakarta. Penelitian ini menggunakan pendekatan kualitatif dengan metode analisis deskriptif. Interview dilakukan secara langsung dengan informan, yang terdiri dari Dekan, Wakil dekan, Ketua Program Studi PAI. Hasil observasi dan dokumentasi diperoleh dari berbagai studi dokumen, naskah, dan arsip yang berkaitan dengan manajemen kurikulum berbasis KKNI. Teknik analisis data menggunakan reduksi data, display data dan verifikasi. Hasil penelitian ini menunjukkan bahwa: a) Kurikulum prodi PAI FAI UMJ telah sesuai dengan acuan kurikulum KKNI yang berlaku dan setiap komponen manajemen kurikulum yang terdiri dari perencanaan, pelaksanaan dan evaluasi kurikulum sudah berjalan dengan baik, walaupun masih terdapat kekurangan dan kelemahan dari setiap proses yang dilakukan; b) Pengembangan manajemen kurikulum harus memperhatikan SOP dan regulasi kurikulum KKNI, namun dalam pelaksanaanya masih belum sepenuhnya berbasis KKNI.

Kata Kunci: manajamen kurikulum, perguruan tinggi Islam, KKNI 


\section{PENDAHULUAN}

Berbagai masalah terjadi pada perguruan tinggi Islam di Indonesia saat ini (Juanda, 2014). Permasalahan tersebut dapat dilihat dari adanya missing link antara lulusan perguruan tinggi dengan dunia kerja. Persoalan pengangguran bukan semata karena ketiadaan pekerjaan, melainkan juga ketidaksesuaian antara jenis pekerjaan dan lulusan yang memenuhi kualifikasi yang dibutuhkan. Artinya, ada sejumlah pekerjaan yang tidak bisa diisi oleh lulusan perguruan tinggi (Maksum, 2015; Ikhwan, 2016).

Permasalahan kurikulum pada perguruan tinggi Islam yang muncul akhir-akhir ini adalah ketidakmampuan menerapkan kurikulum berbasis Kerangka Kualifikasi Nasional Indonesia (KKNI) dengan lancar. Adapun kendalanya adalah faktor ketidaksiapan SDM maupun sistem yang belum memadai. KKNI sebagai kurikulum baru memang membutuhkan waktu yang tidak instan dalam mempersiapkannya, mulai dari perencanaan, sampai evaluasi kurikulumnya. Perencanaan kurikulum berbasis KKNI mengacu pada tuntutan dan kebutuhan stakeholder, sehingga diperlukan evaluasi dan peninjauan kembali secara berkala (Aflahah, 2019).

Munculnya kurikulum KKNI di perguruan tinggi Islam menjadi problematika yang belum selesai sampai sekarang. Sejak KKNI digulirkan melalui Peraturan Presiden Republik Indonesia Nomor 8 Tahun 2012 tentang Kerangka Kualifikasi Nasional Indonesia, terdapat beberapa masalah yang muncul, antara lain mengenai adanya indikasi ketidaksesuaian kualifikasi dalam Standar Kompetensi Lulusan dengan fakta dan realita yang terjadi di lapangan.

Problematika di atas menjadi tuntutan bersama untuk diselesaikan agar tidak menjadi problem yang berkepepanjangan. Maka dari itu, sudah saatnya pergurun tinggi Islam memiliki peran sebagai agent of change dalam menghadapi tantangan pendidikan dan selalu berhasil mengubahnya menjadi peluang (Ekawati, 2018; Sewang \& Halik, 2019). Perguruan tinggi Islam sebagai wadah dalam merencanakan lulusan sebagai manusia insan kamil yang memiliki sifat uswatun hasanah yang dapat menjadi tauladan bagi masyarakat (Saufi \& Hambali, 2019).

Salah satu upaya perguruan tinggi Islam dalam menyelesaikan problematika di atas adalah dengan mengembangkan manajemen kurikulum berbasis KKNI (Jono, 2016). Manajemen kurikulum berbasis KKNI adalah sebuah proses yang dilakukan perguruan tinggi Islam dalam memberikan penyelenggaraan pendidikan sebagai solusi dalam meningkatkan mutu lulusan agar memiliki kompetensi yang dapat diakui serta memberikan layanan kepuasan bagi penggunanya (Kalimantara, 2016; Cui et al., 2018).

Pentingnya manajemen kurikulum KKNI pada perguruan tinggi Islam sebagai suatu sistem pengelolaan kurikulum yang kooperatif, komprehensif, sistemik, dan sistematik dalam rangka mewujudkan ketercapaian tujuan kurikulum dalam rangka pemberian pengakuan kompetensi kerja sesuai dengan struktur pekerjaan di berbagai sektor (Rusman, 2009).

Hal ini dilakukan untuk meningkatkan mutu dan kualitas perguruan tinggi Islam agar dapat bersaing dengan negara-negara maju. Manajemen 
kurikulum KKNI menjadi prioritas yang dapat dilakukan dengan perencanaan, pengembangan, pelaksanaan, dan penilaian kurikulum dalam rangka kesetaraan capaian pembelajaran serta kualifikasi tenaga kerja, baik yang akan belajar atau bekerja di Indonesia maupun sebaliknya apabila akan menerima pelajar atau tenaga kerja dari Indonesia (Lazwardi, 2017; Anih, 2015; Fathoni, 2015).

Pada aspek inilah, keberhasilan perguruan tinggi Islam membutuhkan sebuah manajemen kurikulum. Manajemen kurikulum merupakan salah satu komponen yang memiliki peran strategis dalam sistem pendidikan. Kurikulum merupakan satu sistem program pembelajaran yang dimaksudkan untuk mencapai tujuan institusional pada lembaga pendidikan tinggi, sehingga kurikulum memegang peranan penting dalam mewujudkan perguruan tinggi yang berkemajuan dan berkualitas (Wahyudin, 2016; Syamsu, 2019).

Melihat pentingnya manajemen kurikulum KKNI pada perguruan tinggi Islam, banyak para peneliti melakukan research mengenai kurikulum perguruan tinggi misalnya (Hidayati, 2017; Rahayu, 2020) yang menyatakan tentang pentingnya kurikulum KKNI bagi perguruan tinggi. Penelitian Kisbiyanto (2016) yang menyimpulkankan bahwa manajemen kurikulum di perguruan tinggi dapat menjamin sistem penilaian dan sistem kendali mutu. Hal yang sama dijelaskan pula oleh Badrudin \& Nurdin (2019) bahwa model sistem manajemen informasi kurikulum berbasis CMS dapat berdampak pada sistem pengelolaan perguruan tinggi semakin baik.

Meskipun penelitian mengenai kurikulum perguruan tinggi telah banyak dilakukan, belum ada yang mengkaji tentang bagaimana fungsi-fungsi manajemen terhadap pelaksanaan kurikulum berbasis KKNI di perguruan tinggi Islam. Oleh karena itu, penelitian ini bertujuan untuk menganalisis penyusunan, pelaksanaan dan evaluasi dalam pengembangan kurikulum berbasis KKNI pada Program Studi Pendidikan Agama Islam (PAI), Fakultas Agama Islam (FAI) Universitas Muhammadiyah Jakarta.

\section{METODE PENELITIAN}

Pendekatan penelitian yang digunakan adalah pendekatan kualitatif jenis deskriptif. Sumber data primer diperoleh dari hasil wawancara dengan Dekan, Wakil Dekan, Kaprodi, Dosen-dosen PAI di Universitas Muhammadiyah Jakarta. Peneliti juga mengambil data melalui observasi yang dilakukan pada saat perkuliahan berlangsung. Sementara itu, dokumen yang berkenaan dengan fokus penelitian dan aspek pendukung lainnya, seperti; Buku Pedoman Pengembangan Kurikulum PTKI, Buku Pedoman Penyusunan Kurikulum, Visi-Misi, Draf Kurikulum prodi PAI, dan SKL, CPL pada PTKI, dikumpulkan sesuai dengan fokus penelitian. Teknik analisis datanya dilakukan melalui reduksi data, display data, dan penarikan kesimpulan yang dilakukan secara sirkuler. 


\section{HASIL DAN PEMBAHASAN}

\section{Perencanaan Kurikulum Berbasis KKNI}

Perencanaan kurikulum yang dilakukan oleh Program Studi Pendidikan Agama Islam (PAI), Fakultas Agama Islam (FAI) Universitas Muhammadiyah Jakarta berbasis KKNI mengacu kepada regulasi yang dikeluarkan oleh Pemerintah melalui kebijakan Peraturan Presiden Republik Indonesia Nomor 8 Tahun 2012. Ditambah beberapa regulasi Peraturan Menteri Pendidikan dan Kebudayaan No. 49 tahun 2014 tentang Standar Nasional Pendidikan Tinggi, Perpres No. 08 tahun 2012 dan Pemendikbud No. 73 tahun 2013 tentang Capaian Pembelajaran Sesuai dengan Level KKNI, UU PT No. 12 tahun 2012 pasal 29 tentang Kompetensi lulusan ditetapkan dengan mengacu pada KKNI, Permenristek dan Dikti No. 44 tahun 2015 tentang Standar Nasional Pendidikan Tinggi, PMA No 1 Tahun 2016 tentang Ijazah, Transkip Nilai dan SKPI serta Perdirjen No 25 tahun 2018 Tentang SKL dan CPL Program Studi Jenjang Sarjana.

Sejalan dengan regulasi, tuntutan yuridis tentang Standar Nasional Pendidikan Tinggi dan ketentuan tentang Kerangka Kualifikasi Nasional Indonesia (KKNI), maka kurikulum dikembangkan dengan menyesuaikan pada pijakan landasan tersebut. Program Studi Program Studi Pendidikan Agama Islam (PAI), Fakultas Agama Islam (FAI) Universitas Muhammadiyah Jakarta telah mengimplementasikan kurikulum berbasis KKNI sejak tahun 2015. Proses penyusunan kurikulum berbasis KKNI sudah dilakukan sejal awal tahun 2015 dan secara berkesinambungan diperbaharui dengan menyesuaikan pada kebijakan terbaru, termasuk hasil workshop konsorsium atau asosiasi Prodi PAI Se-Indonesia.

Perumusan capaian lulusan program studi Program Studi Pendidikan Agama Islam (PAI) sudah dievaluasi berdasarkan kurikulum yang lama, yakni mengkaji seberapa jauh capaian pembelajaran telah terbukti dimiliki oleh lulusan dan dapat beradaptasi terhadap perkembangan kehidupan. Informasi untuk pengkajian ini bisa didapatkan melalui penelusuran lulusan, masukan pemangku kepentingan, asosiasi profesi atau kolokium keilmuan, dan kecenderungan perkembangan keilmuan/keahlian ke depan. Hasil dari kegiatan ini adalah rumusan capaian pembelajaran baru (Busahdiar, 2020).

Perumusan capaian lulusan program studi Program Studi Pendidikan Agama Islam (PAI) dimulai dengan analisis SWOT, penetapan visi keilmuan prodi, melalui kebijakan perguruan tinggi dalam pengembangan prodi, di samping juga melakukan analisis kebutuhan, serta mempertimbangkan masukan pemangku kepentingan, asosiasi profesi/keilmuan. Semua tahap ini, rumusan capaian pembelajaran lulusan yang dihasilkan harus memenuhi ketentuan yang tercantum dalam SN-Dikti dan KKNI.

Hasil evaluasi diri dengan menggunakan analisis SWOT untuk menemukan kekuatan, kelemahan, peluang, dan ancaman Program Studi Pendidikan Agama Islam (PAI) dan memperhatikan visi program studi, serta melakukan market signal, tracerstudy (need assessment) kepada para alumni dan memperhatikan masukan asosiasi dan stakeholders, maka dapat dirumuskan Profil Program Studi Pendidikan Agama Islam (PAI) dan learning Outcomes. 
Penelusuran peran lulusan sangat penting agar dapat memetakan bidang keahlian atau bidang kerja tertentu setelah mereka bekerja. Profil Program Studi Pendidikan Agama Islam (PAI) dapat ditetapkan berdasarkan hasil kajian terhadap kebutuhan lembaga pendidikan serta kebutuhan dalam mengembangkan ilmu pengetahuan dan teknologi. Maka dari itu, profil program studi PAI disusun oleh kelompok prodi sejenis, sehingga terjadi kesepakatan yang dapat diterima dan dijadikan rujukan secara nasional. Untuk dapat menjalankan peran-peran yang dinyatakan dalam profil tersebut diperlukan "kemampuan" yang harus dimiliki (Tajudin, 2020).

Profil lulusan Program Studi Pendidikan Agama Islam (PAI), Fakultas Agama Islam (FAI) Universitas Muhammadiyah Jakarta harus mencerminkan unsur ketrampilan khusus (kemampuan kerja) dan penguasaan pengetahuan sesuai dengan CPL yang sudah disepakati oleh Kementerian Agama (Kemenag), sedangkan yang mencakup sikap dan keterampilan umum dapat mengacu pada rumusan yang telah ditetapkan dalam SN-Dikti sebagai standar minimal, yang memungkinkan ditambah sendiri untuk memberi ciri lulusan perguruan tinggi.

Atas dasar regulasi inilah rektor Universitas Muhammadiyah Jakarta (UMJ) membuat surat edaran kepada semua Dekan Fakultas tentang kewajiban masing-masing prodi untuk meninjau kurikulum prodi berdasarkan kurikulum KKNI. Surat edaran inilah yang menjadi dasar Dekan setiap fakultas di UMJ untuk membuat surat kepada masing-masing prodi (Kartika, 2020). Adapun mekanisme penyusunan kurikulum berbasis KKNI yang dilakukan pada FAI UMJ dapat dijelaskan sebagai berikut;

Pertama, Dekan membuat surat tugas kepada masing-masing prodi untuk menyusun kurikulum berdasarkan KKNI. Surat tugas ini berisikan tugas untuk menyusun kurikulum Program Studi PAI yang terdiri Dekan, Wadek, Kaprodi PAI dan dosen tetap PAI.

Kedua, Kaprodi dan Sekretaris prodi PAI menjadwalkan rutin tiap minggu untuk mengadakan rapat tinjauan kurikulum. Rapat kurikulum ini dihadiri oleh dekan, wadek serta dosen tetap PAI untuk meninjau kurikulum dan melihat sejauh mana kesesusaian profile lulusan, capaian pembelajaran, pemilihan bahan kajian (keluasan, kedalaman, tingkat penguasaan), CPL (sikap, keterampilan umum, keterampilan khusus, pengetahuan) susunan mata kuliah dan besaran SKS.

Ketiga, Dekan FAI menugaskan Kaprodi dan Sekprodi untuk mengikuti kegiatan workshop kurikulum KKNI yang diselenggarakan oleh Kemenag. Hasil kegiatan workshop ini nantinya menjadi bahan pendalaman Kaprodi serta tim pengembangan kurikulum untuk dijadikan masukan dalam pengembangan kurikulum PAI berbasis KKNI.

Keempat, prodi PAI menyelenggarakan diskusi ilmiah dengan mengundang para ahli kurikulum, diantaranya guru besar UIN Jakarta untuk mereview kurikulum dan memberikan masukan perbaikan kepada kurikulum PAI berbasis KKNI yang sedang dikembangkan. Selain mengundang para ahli kurikulum, kaprodi PAI mengundang para dosen tetap di lingkungan FAI UMJ untuk hadir dan menjadi peserta aktif. 
Pada Tahap perencanaan ini, semuanya berada di bawah arahan pimpinan FAI yakni; Dekan, Wadek, kaprodi dan UKM supaya dapat dikelola dengan hati-hati, serta dilakukan rencana kegiatan, jadwal kegiatan agar semua terpantau dan dapat berjalan dengan baik.

Dapat dijelaskan bahwa; penyusunan kurikulum prodi PAI belum disusun berdasarkan pedoman KKNI. Tahap-tahap penyusunan sudah dilaksanakan dengan baik, namun penyusunan kurikulum masih setengahsetengah KKNI. Hal ini dapat dilihat dari CPL yang dibuat belum berdasarkan KKNI. Profile lulusan yang disusun dituangkan ke dalam kurikulum sudah mengarah kepada guru PAI professional dengan keunggulan di bidang IT. Tidak sekedar memahami agama dan bukan pula sebagai ulama. Maka dari itu, Kaprodi PAI sejak awal sudah mengarahkan mahasiswa sebagai guru PAI professional.

Busahdiar (2020) mengungkapkan bahwa Kurikulum Prodi PAI FAI UMJ dikembangkan dengan mengacu pada model dan desain kurikulum berbasis KKNI. Namun pengembangan kurikulum PAI masih setengahsetengah dalam pengembangannya. Kurikulum disusun dengan tertebih dahulu merumuskan Profil lulusan yang diharapkan oleh Program studi selanjutnya dirumuskan tentang capaian pembelajaran (learning outcomes) untuk mencapai profil lulusan yang diharapkan.

Hal senada dijelaskan Kartika (2020) bahwa pengembangan kurikulum berbasis KKNI pada dasarnya berusaha untuk membangun kesetaraan dan pengakuan kualifikasi antara SDM Indonesia dengan SDM asing. Karena itu, model pengembangan kurikulumnya dimulai dari penentuan profil lulusan program studi. Profil lulusan adalah jawaban terhadap pertanyaan program studi ini akan menghasilkan lulusan seperti apa? atau 'peran apa' yang dapat dilakukan oleh lulusan di masyarakat (outcomes). Dalam penentuan profil lulusan ini diperlukan analisis SWOT terlebih dahulu dengan mempertimbangkan nilai-nilai universitas dan visi keilmuan dari program studi, serta dilakukan tracer study melalui need assessment dan market signal, sehingga perlu mempertimbangkan masukan-masukan asosiasi dan stakeholders.

Kaprodi PAI dalam menyusun kurikulum berdasarkan buku pedoman penyusunan kurikulum yang dibuat oleh Kementerian Riset, Teknologi dan Pendidikan Tinggi Direktorat Jenderal Pembelajaran dan Kemahasiswaan Direktorat Pembelajaran tahun 2016. Namun kurikulum PAI yang disusun belum sesuai dengan pedoman. Hal ini dapat dilihat pada Capaian Pembelajaran Lulusan yang belum sesuai KKNI, yang mana CPL belum mengarahkan kepada CPL yang sudah ditetapkan oleh KKNI (Busahdiar, 2020). Paling tidak Penyusunan kurikulum berisi kegiatan penyusunan konsep sampai dengan penyusunan mata kuliah dalam semester dari suatu program studi. Secara keseluruhan tahapan perancangan kurikulum dibagi dalam tiga bagian kegiatan, yakni; 1) Perumusan capaian pembelajaran lulusan (CPL); 2) Pembentukan mata kuliah; dan 3) Penyusunan mata kuliah (kerangka kurikulum) (Kemenristekdikti, 2016) Pembentukan mata kuliah yang disusun oleh Kaprodi PAI sebanyak 64 mata kuliah dan 154 sks. 
Perencanaan kurikulum di atas setidaknya memuat seperangkat rencana dan pengaturan mengenai capaian pembelajaran lulusan (Millah \& Machali, 2013; Paminto et al., 2018; Wang, 2019), bahan kajian, proses, dan penilaian yang digunakan sebagai pedoman penyelenggaraan program studi. Tahapan yang dilakukan oleh pengelola program studi dalam menyusun dan mengembangkan kurikulum sebagai berikut; Penetapan Profil Lulusan, Penetapan Capaian Pembelajaran Lulusan (CPL), Penetapan Bahan Kajian, Penentuan Mata Kuliah, Penetapan Besaran SKS Mata Kuliah, Penyusunan Struktur Kurikulum, Proses Pembelajaran, Penilaian, dan Penyusunan Rencana Pembelajaran Semester (Kemenag, 2018).

Berdasarkan proses tahapan penyusunan kurikulum mengacu kepada point-point di atas, dapat disimpulkan bahwa semua tahapan tersebut belum sepenuhnya dilakukan oleh Kaprodi PAI dalam menyusun dan mengembangan kurikulum PAI berbasis KKNI.

\section{Pelaksanaan Kurikulum Berbasis KKNI}

Kurikulum pada Program Studi Pendidikan Agama Islam (PAI), Fakultas Agama Islam (FAI) Universitas Muhammadiyah Jakarta diterapkan melalui proses pembelajaran di dalam dan di luar kelas. Pelaksanaan kurikulum juga dijabarkan melalui sejumlah mata kuliah yang sudah disusun oleh Kaprodi PAI berbasis KKNI setiap semester. Jumlah Mata Kuliah (MK) pada prodi PAI FAI UMJ adalah 57 MK dengan jumlah SKS 147, terdiri dari 56 Mata kuliah Wajib, yang dijabarkan 4 mata kuliah nasional dengan 8 sks, 6 MK Wajib Universitas dengan 12 sks, 16 MK Wajib Fakultas dengan 39 sks, dan 31 MK Wajib Prodi dengan 88 sks; dan 1 Mata Kuliah Pilihan.

Pelaksanaan kurikulum dimulai dengan diadakannya rapat dosen di awal perkuliahan dengan menjadwalkan jam mengajar serta pembagian mata kuliah sesuai dengan keahlian dosen. Pada rapat ini, dosen diminta untuk membuat RPS (Rencana Pembelajaran Semester) yang disesuaikan dengan profil lulusan dan CP (Capaian Pembelajaran) Prodi PAI. Kemudian, Dekan membuatkan Surat Tugas kepada dosen tetap berdasarkan bidang keahlian atau sejenis konsorsium keilmuan dengan mata kuliah yang sama untuk menyusun RPS sebagai rencana kegiatan belajar mahasiswa.

Bentuk pembelajarannya dilakukan melalui: pertama, kuliah (tatap muka, tugas terstrutur dan tugas mandiri); kedua, responsi dan tutorial; ketiga, seminar; dan keempat, praktikum melalui kegiatan PPL, qiraat dan ibadah, seminar proposal, dan KKN. Model-model pembelajaran mengacu pada pendekatan berbasis pada pengalaman dan aktivitas belajar mahasiswa (Busahdiar, 2020).

Karakteristik proses pembelajaran pada Prodi PAI bersifat interaktif, holistik, integratif, saintifik, kontekstual, tematik, efektif, kolaboratif, dan berpusat pada mahasiswa. Karakteristik proses tersebut selanjutnya tercermin dalam penyusunan perencanaan proses pembelajaran dalam bentuk rencana program semester (RPS).

Pelaksanaan kurikulum prodi PAI memperhatikan mata kuliah wajib yang telah di atur dalam Undang-Undang Nomor 12 tahun 2012 tentang 
Pendidikan Tinggi, bahwa mata kuliah wajib yang harus dimasukkan oleh setiap program studi pada PTKI, yaitu; 1) Agama; 2) Pancasila; 3) Kewarganegaraan; dan 4) Bahasa Indonesia. Kajian agama pada PTKI dikembangkan menjadi beberapa mata kuliah sesuai dengan CPL yang ditentukan. Selain empat mata kuliah tersebut merupakan mata kuliah wajib yang disusun Universitas, Fakultas, dan Program Studi dengan mempertimbangkan kajian pencirian Capaian Pembelajaran (CP) sesuai bahan kajian yang telah dilakukan dan memasukkan mata kuliah Kemuhammadiyahan sebagai ciri khas mata kuliah Universitas. Ada juga Mata kuliah pilihan yang telah disusun prodi PAI yang merupakan mata kuliah penunjang pada mata kuliah wajib. Mahasiswa diharuskan mengambil mata kuliah pilihan tersebut sesuai dengan minat dan sesuai dengan ketentuan berlaku pada kebijakan masing-masing prodi.

Penentuan mata kuliah, perlu memperhatikan beberapa hal, antara lain: pertama, pola penentuan mata kuliah dapat dilakukan dengan mengelompokkan bahan kajian yang setara, kemudian memberikan nama pada kelompok bahan kajian tersebut; dan kedua, nama mata kuliah disesuaikan kelazimannya dalam program studi sejenis. Hal tersebut didasarkan atas kesamaan rumusan CPL pada program studi (Kemenag, 2018). Dengan demikian, prodi perlu melakukan kajian secara mendalam dalam menentukan mata kuliah yang memenuhi berbagai kompetensi yang diharapkan, mencakup kompetensi sikap, pengetahuan, keterampilan umum, dan keterampilan khusus.

Sementara itu, dalam pendistribusian mata kuliah prodi setiap semester dapat dilakukan dengan dua cara, yaitu: pertama, cara serial didasarkan pada pertimbangan adanya struktur atau logika keilmuan/keahlian yang dianut, yaitu pandangan bahwa suatu penguasaan pengetahuan tertentu diperlukan untuk mengawali pengetahuan selanjutnya (prasyarat); dan kedua, cara paralel didasarkan pada pertimbangan proses pembelajaran. Pendekatan yang digunakannya adalah pembelajaran secara terintegrasi baik keilmuan maupun proses pembelajaran supaya mendapatkan hasil belajar yang lebih baik (Kemenag, 2018).

Implementasi kurikulum mengalami banyak perubahan dalam pelaksanaannya (Gordon, 2018). Perubahan tersebut mengikuti regulasi dari pemerintah agar pengelola pendidikan dapat menyesuaikan dengan perkembangaan kurikulum (Pawilen et al., 2018). Bagi Kaprodi yang update dalam perkembangan kurikulum, maka tidak memiliki kendala dalam melaksanakannya. Permasalahannya bahwa kurikulum mengalami perubahan seiring dengan perkembangan pengetahuan (Solikhah, 2015). Pelaksanaan kurikulum prodi PAI FAI UMJ berbasis KKNI dilakukan dengan proses pembelajaran orang dewasa dan tentunya menyenangkan. Hal ini dilakukan berdasarkan dengan perkembangan teori pembelajaran yang salah satunya sebagaimana tertuang dalam peraturan Menteri Pendidikan Nasional No 22 Tahun 2006 tentang Standar Isi (Fathurrochman, 2017). 
Pelaksanaan kurikulum merupakan aktivitas interkasi antara pendidik dan peserta didik yang memiliki komunikasi dari berbagai arah (Lewis et al., 2019). Implementasi kurikulum dapat dilaksanakan apabila pendidik dapat memahami apa yang seharusnya diajarkan kepada peserta didik (Cahapay, 2020). Hal ini terkait dengan materi, konsep, metode, pendekatan, media serta lingkungan pendidikan. Sebagai sebuah institusi perguruan tinggi Islam, prodi PAI memberikan proses pembelajaran yang tidak hanya unggul pada aspek kognitif saja, melainkan unggul dalam afektif dan psikomotorik.

Pelaksanaan kurikulum prodi PAI mengintegrasikan antara regulasi dari Kemenristekdikti dan Kemenag yang kedua lembaga ini menjadi payung dalam pelaksanaan kurikulum. Tujuannya adalah memberikan kemudahan bagi mahasiswa dalam mengikuti proses perkuliahan. Kegiatan perkuliahan bukan hanya sekedar tatap muka melainkan tugas terstruktur dan tugas mandiri. Bahan perkuliahan dibuat semenarik mungkin oleh dosen yang mengajar dengan mengkombinasikan pembelajaran e-learning dan konvensional (Huda, 2017).

Dengan demikian, bahwa pelaksanaan kurikulum prodi PAI sudah berjalan dengan baik, namun masih terdapat kekurangan. Sebagian dosen masih ada yang belum melakukan pembelajaran sesuai dengan KKNI. Misalkan dosen yang mengajar hanya sekedar tatap muka dan tidak memberikan tugas terstruktur dan tugas mandiri.

Perencanaan kurikulum yang dilakukan oleh Kaprodi PAI melalui tahapan proses mendiskusikan dan mengkoordinasikan tahapan-tahapan dari penyusunan kurikulum yang nantinya dijadikan sebagai perencanaan program prioritas (Sholihah, 2017). Proses ini menentukan bagaimana seharusnya kurikulum itu menjadi sebuah tujuan yang dapat dicapai (Chapman, et al., 2000). Berbagai pertimbangan secara matang disusun sebagai asumsi-asumsi dari segi positif dan negatif (Huda, 2017).

\section{Evaluasi Kurikulum Berbasis KKNI}

Evaluasi kurikulum prodi PAI FAI UMJ dilaksanakan oleh unit kendali mutu (UKM) internal FAI UMJ dan dikontrol langsung oleh Kaprodi PAI. Namun pelaksanaan evaluasi kurikulum sampai sekarang belum pernah dilaksanakan. Hal ini disebabkan karena belum adanya SOP yang jelas terkait evaluasi kurikulum. Unit kendali mutu FAI UMJ bertugas menjamin mutu segala kegiatan dalam pelaksanaan kurikulum. Mulai dari evaluasi dosen, evaluasi tenaga kependidikan, evaluasi sarpras, evaluasi perkuliahan, dan evaluasi kurikulum melalui tracer study.

Evaluasi pelaksanaan pembelajaran dijadikan sebagai bahan diskusi pimpinan FAI untuk memperbaiki dan menindaklanjuti perbaikan pelaksanaan pembelajaran. Mulai dari sarana dan prasarana, RPS, buku ajar, handout perkuliahan dan soal ujian. Semuanya tidak luput dari proses evaluasi yang dilakukan pada prodi PAI. Setiap minggu pada hari senin pimpinan FAI melakukan kontrol proses perkuliahan dengan mengadakan sebuah pertemuan yang di dalamnya mendiskusikan tentang pelaksanaan pembelajaran. Seluruh Kaprodi hadir memberikan informasi terkait pelaksanaan perkuliahan yang 
berlangsung. Kontrol ini menjadi sebuah sistem dalam menjamin kualitas pelaksanaan kurikulum pada prodi PAI.

Kegiatan evaluasi kurikulum juga dilakukan pada setiap akhir semester. Pencapaian mutu yang telah ditetapkan menjadi standar prodi PAI dalam menyelenggarakan proses pembelajaran. Apakah input, proses dan output sudah berjalan dengan baik. Pembenahan metode dan penyajian materi dibahas pada kegiatan evaluasi kurikulum karena metode setiap dosen berbeda sesuai kreativitas masing-masing (Jauhari et al., 2017; Aboagye \& Yawson, 2020). Tujuan dari evaluasi kurikulum ini untuk mengetahui bagaimana tingkat keberhasilan proses kurikulum KKNI dilaksanakan dan sebagai bahan diskusi dalam pengembangan kurikulum di prodi PAI FAI UMJ.

Kaprodi PAI melaksanakan kegiatan evaluasi kurikulum melalui RPS yang dibuat oleh masing-masing dosen PAI. Setiap dosen diminta untuk membuat dan melaporkan RPS bertujuan untuk mengetahui sejauh mana perkembangan bahan ajar dan materi yang dibuat oleh dosen dengan menyesuaikan capaian pembelajaran lulusan. Setiap akhir awal semester Kaporodi PAI meninjau ulang RPS setiap dosen dan mengumpulkan dosendosen yang mengampu mata kuliah yang sama. Dosen pengampu mata kuliah yang sama di evaluasi apakah RPS yang dibuat memiliki keseragaman atau tidak.

Evaluasi kurikulum dilakukan oleh prodi PAI dengan menggunakan sistem penjamin mutu yang dilaksanakan oleh gugus kendali mutu prodi PAI. Evaluasi bertujuan untuk mengetahui sejauh mana output dari kurikulum itu direncanakan (Cooper, 2017; Pawilen et al., 2018). Bagaimana hasil dari pelaksanaan kurikulum dan apakah sudah sesuai dengan kebutuhan pasar (Nasbi, 2017).

Evaluasi kurikulum prodi PAI dilakukan dengan melihat output dari proses pembelajaran yang disesuaikan dengan RPS bermuatan keilmuan integrasi interkoneksi antara CPL, CPMK, sub CPMK, serta instrumen penilaian pembelajaran berdasarkan indikator pencapaian kemampuan akhir tiap tahapan belajar (Hidayati, 2016).

\section{KESIMPULAN}

Pengembangan manajemen kurikulum berbasis KKNI yang dilaksanakan pada prodi PAI sudah terlaksana cukup baik. Hal ini dapat dilihat pada aspek perencanaan, pelaksanaan dan evaluasi kurikulum yang sudahterlaksana namun masih perlu melakukan perbaikan mutu. Manajemen kurikulum berbasis KKNI sangat menetukan mutu lulusan perguruan tinggi Islam. Aspek-aspek kurikulum dapat semakin berkualitas apabila pimpinan dan stakeholder berkomitmen melakukan optimalisasi dalam melaksanakan manajemen kurikulum berbasis KKNI dengan memperhatikan standar mutu. Semua civitas akademika dan tenaga kependidikan berkomitmen melakukan perbaikan dan terus menembangkan kurikulum KKNI yang dilaksanakan di PAI FAI UMJ. Sejatinya kurikulum yang baik adalah kurikulum yang mengikuti perkembanganilmu dan teknologi yang berbasis pada masyarakat serta nilai-nilai Al-Qur'an. 
Pengembangan manajemen kurikulum pada peguruan tinggi Islam harus memperhatikan SOP dan regulasi kurikulum KKNI. Kaprodi PAI sangat menentukan arah dan tujuan kurikulum yang telah dibuat. Kurikulum PAI harus bisa merespon tuntutan dan perkembangan pendidikan Islam dewasa ini. Dengan begitu, kualitas kurikulum perguruan tinggi Islam dapat bersaing dengan dunia global.

\section{DAFTAR PUSTAKA}

Aboagye, E., \& Yawson, J. A. (2020). Teachers' perception of the new educational curriculum in Ghana. African Educational Research Journal, $8(1), 6-12$.

Anih, E. (2015). Manajemen Implementasi Kebijakan Pengembangan Kurikulum di Perguruan Tinggi berbasis Kompetensi. Jurnal Pendidikan UNSIKA, 3(1), 1-21

Badrudin, B., \& Nurdin, R. (2019). SIM (Sistem Informasi Manajemen) Kurikulum Perguruan Tinggi Keagamaan Islam Berbasis CMS Wordpress. Ta'dib, 22(1), 12. https://doi.org/10.31958/jt.v22i1.1416

Busahdiar. (2020). Intreview. Banten.

Cahapay, M. B. (2020). A Case Study of Curriculum Unpacking Practices of a Kindergarten Teacher. Journal of Curriculum and Teaching, 9(2), 1-8. https://doi.org/10.5430/jct.v9n2p1

Chapman, S., Wright, P., \& Pascoe, R. (2000). "Content without Context is Noise": Looking for Curriculum Harmony in Primary Arts Education in Western Australia. International Journal of Education $\mathcal{E}$ the Arts Christopher, 19(2), 1-26. https://doi.org/10.1177/1321103X0001500110

Cooper, T. (2017). Curriculum Renewal: Barriers to Successful Curriculum Change and Suggestions for Improvement. Journal of Education and Training Studies, 5(11), 115-128. https:// doi.org/10.11114/jets.v5i11.2737

Ekawati, M. S. dan K. S. (2018). Moderasi Kurikulum Perguruan Tinggi Islam dalam Deradikalisasi Agama di Indonesia. Istiqro', 16(1), 139-178. Retrieved from http:/ / istiqro.kemenag.go.id/index.php/istiqro/article/view/97/82

Fathoni M. (2015). Pendidikan Islam dan Pendidikan Nasional: Paradigma Baru. Jakarta: Departemen Agama RI: Direktorat Kelembagaan Agama Islam.

Fathurrochman, I. (2017). Implementasi Manajemen Kurikulum dalam Upaya Meningkatkan Mutu Santri Pondok Pesantren Hidayatullah / Panti Asuhan Anak Soleh Curup. TADBIR: Jurnal Studi Manajemen Pendidikan Vol., 1(1), 85-104.

Gordon, S. (2018). Supervision's New Challenge: Facilitating a Multidimensional Curriculum. Journal of Educational Supervision, 1(2), 1732. https://doi.org/10.31045/jes.1.2.2 
Hidayati, W. (2017). Manajemen Kurikulum Pendidikan Agama Islam dan Budi Pekerti Jenjang SMA Bermuatan Keilmuan Integrasi Interkoneksi. MANAGERIA: Jurnal Manajemen Pendidikan Islam, 1(2), 195-225. https:// doi.org/10.14421/manageria.2016.12-03

Huda, N. (2017). Manajemen Pengembangan Kurikulum. Al-Tanzim: Jurnal Manajemen Pendidikan Islam, 1(2), 52-75. https://doi.org/10.33650/altanzim.v1i2.113

Ikhwan, A. (2016). Perguruan Tinggi Islam dan Integrasi Keilmuan Islam. AtTajdid: Jurnal Ilmu Tarbiyah, 5(2), 159-187.

Jauhari, M., Rofiki, M., \& Farisi, Y. Al. (2017). Authentic Assessment dalam Sistem Evaluasi Pengembangan Kurikulum 2013. Pedagogik: Jurnal Pendidikan, 4(1), 103-116.

Jono, A. A. (2016). Studi Implementasi Kurikulum Berbasis KKNI pada Program Studi Pendidikan Bahasa Inggris di LPTK Se-Kota Bengkulu. Manhaj, 4(1), 57-68.

Juanda, A. (2014). Integrasi Ilmu Alam (Sains) dan Agama Berbasis Kurikulum Grass Roots di Perguruan Tinggi Islam. Scientiae Educatia, 3(1), 79-88.

Kalimantara, B. (2016). Manajemen Quality Assurance sebagai Upaya Meningkatkan Kepercayaan Masyarakat Terhadap Sekolah. Jurnal Manajemen Dan Supervisi Pendidikan, 1(1), 52-59. https://doi.org/10.17977/um025v1i12016p052

Kartika. (2020). Interview. Banten.

Kisbiyanto. (2016). Manajemen Kurikulum Dalam Perspektif Anti-Radikalisme. Addin, 10(1), 181-206. https://doi.org/10.21043/addin.v10i1.1134

Lazwardi, D. (2017). Manajemen Kurikulum Sebagai Pengembangan Tujuan Pendidikan. Al-Idarah: Jurnal Kependidikan Islam, 7(1), 202-215

Lewis, G. D., Liace, K. F., \& Braun, P. A. (2019). All Hands on Deck in Curriculum and Instructional Processes. World Journal of Education, 9(5), 83-99. https://doi.org/10.5430/wje.v9n5p83

Maksum, A. (2015). Model Pendidikan Toleransi di Pesantren Modern dan Salaf. Jurnal Pendidikan Agama Islam, 3(1), 83-108.

Millah, S., \& Machali, I. (2013). Pengembangan Kurikulum Perguruan Tinggi Pesantren: Studi pada Al-Ma'had Al-Aly Pondok Pesantren Situbondo, al-Munawwir Krapyak dan Wahid Hasyim Sleman. Jurnal An Nur, 5(2), 262-289.

Paminto, J., Rosiana, T., Budiyono, \& Budisantoso, H. T. (2018). Implementasi Kurikulum 2013 di Sekolah Pesantren dengan Sistem Boarding School. Indonesian Journal of Curriculum and Educational Technology Studies, 6(1), 46-58.

Pawilen, G. T., B, I. S. S., C, S. J. G. M., \& Buhat, T. A. V. (2018). Developing a Curriculum for the Transition Program of Special Learners in the Philippines. International Journal of Curriculum and Instruction, 10(1), 1-20.

Rahayu, R. I. (2020). Manajemen Pengembangan Kurikulum Kecakapan Hidup (Life Skills) di Perguruan Tinggi Berbasis Pondok Pesantren (Studi Multisitus di IAIQ, INKAFA, dan STAIFI). Universitas Negeri Malang. 
Sanjaya, W. (2008). Perencanaan E Desain Sistem Pembelajaran. Jakarta: Prenada Media Group.

Saufi, A., \& Hambali. (2019). Menggagas Perencanaan Kurikulum Menuju Sekolah Unggul. Al-Tanzim: Jurnal Manajemen Pendidikan Islam, 3(1), 2954.

Sewang, A., \& Halik, A. (2019). Model Manajemen Pembelajaran Pendidikan Islam Berbasis Masalah: Studi Kasus pada Jurusan Tarbiyah dan Adab IAIN Parepare. JPPI (Jurnal Pendidikan Islam Pendekatan Interdisipliner, 3(1), 1-15.

Sholihah. (2017). Desain Pengembangan Kurikulum Pendidikan Agama Islam. KUTTAB, 1(2), 168-179.

Syamsu, S. (2019). Manajemen Kurikulum Pendidikan Al-Islam dan Kemuhammadiyahan di Sekolah Tinggi Keguruan dan Ilmu Pendikan Muhammadiyah Palopo. Journal of Social-Religion Research, 4(1), 61-72.

Wahyudin, D. (2016). Manajemen Kurikulum dalam Pendidikan Profesi Guru (Studi Kasus di Universitas Pendidikan Indonesia). Jurnal Kependidikan, 46(2), 259-270. https:/ / doi.org/10.1017/CBO9781107415324.004

Wang, T. (2019). Competence for Students' Future: Curriculum Change and Policy Redesign in China. ECNU Review of Education, 2(2), 234-245. https://doi.org/10.1177/2096531119850905 